7. Reprod. Fert. (1970) 21, 191-193

\title{
CHANGES IN THE ULTRASTRUCTURE OF CHINCHILLA SPERMATOZOA IN DIFFERENT DILUENTS
}

\author{
P. HEALEY* AND BARBARA J. WEIR \\ Wellcome Institute of Comparative Physiology, \\ Zoological Society of London, Regent's Park, London, N.W.1
}

(Received 6th August 1969)

During the search for a suitable medium in which to freeze spermatozoa of the chinchilla (Chinchilla laniger), samples taken from ten males by electro-ejaculation (Healey \& Weir, 1967) were pooled and studied after treatment with different diluents. All the samples contained a large proportion of motile spermatozoa and no samples were discarded before treatment.

One aliquot of undiluted semen was dropped into $2 \%$ buffered osmium tetroxide at $\mathrm{pH} \mathrm{7.4} \mathrm{(Palade,} \mathrm{1952)} \mathrm{and} \mathrm{other} \mathrm{aliquots} \mathrm{were} \mathrm{diluted} \mathrm{in} 0.5 \mathrm{ml}$ of Baker's fluid (Baker, 1931), normal Ringer (8.5 g sodium chloride, $0.42 \mathrm{~g}$ potassium chloride and $0.25 \mathrm{~g}$ calcium chloride/litre water), half-strength Ringer or double-strength Ringer. The undiluted semen solidified immediately in the fixative and only the outer layer was used. The sperm suspensions in the different diluents were left at room temperature for $10 \mathrm{~min}$ and a sample examined under the light microscope; the rest was fixed in $1 \mathrm{ml}$ of the buffered osmium tetroxide for $2 \mathrm{hr}$ at room temperature. The sample was centrifuged at $2000 \mathrm{rev} / \mathrm{min}$ for $10 \mathrm{~min}$ and the resulting pellet of fixed spermatozoa processed by rapid dehydration through ascending grades of alcohol and embedded in Araldite (Glauert \& Glauert, 1958). Sections were cut on a Huxley ultramicrotome (Cambridge Instrument Co. Ltd) and collected on 200-mesh grids without supporting films. At least 100 spermatozoa in each sample were examined with an AEI-EM 6B electron microscope. Some sections were stained with lead citrate for 15 to 30 min (Reynolds, 1963).

Chinchilla spermatozoa are small, the total length being about $50 \mu$ and the head length about $6.5 \mu$. The mid-piece is nearly twice as long as the head and there is a long tapering tail. Like the guinea-pig (Fawcett, 1965), the nucleus is flattened and appears triangular in sagittal aspect and oval (about $2.5 \mu$ wide) in surface view. In the electron microscope, the spermatozoa were seen only in sagittal or oblique section. Plate 1, Figs. 1 to 3 illustrate the appearance of parts of the ejaculated chinchilla spermatozoon (cf. Fawcett \& Phillips, 1969, on epididymal spermatozoa). The large curved acrosome which covers the anterior two-thirds of the head does not contain an electron-dense area, or apical body, as has been described for some other species (Nicander \& Bane, 1966; Healey, 1969). The outer membrane of the head readily becomes

* Present address: Huntingdon Research Centre, Huntingdon, Hunts. 
detached from the acrosome region but is usually firmly adherent behind the termination of the acrosome (Pl. 1, Fig. 2 and Pl. 2, Fig. 7). This outer membrane can be resolved as a double one (Pl. 1, Fig. 1) but it is not clear whether it covers only the head. The nucleus, which is also bounded by a double membrane (Pl. 1, Fig. 1), occupies most of the head volume but the subacrosomal substance can be seen between the acrosome and the nucleus (Pl. 1, Fig. 1). This electrondense material is considered to be a definite structure in the chinchilla and cross sections of heads show that it covers the whole of the nucleus as described in the rat by Piko \& Tyler (1964). Two electron-dense fibres terminate at the single neck centriole (Pl. 1, Fig. 2) but do not appear to be attached to the main central fibres. The mitochondria are helically arranged and there is no distinct annulus at the mid-piece-tail junction (Pl. 1, Fig. 3). A cytoplasmic droplet (Pl. 1, Fig. 3) may be present anywhere along the mid-piece or tail.

No differences were noted between spermatozoa fixed directly in osmium tetroxide and those examined after fixation within the copulatory plug. Spermatozoa in normal and double-strength Ringer solutions (Pl. 2, Figs. 6 and 7) were motile and showed normal morphology although the outer membrane was slightly detached round the acrosome in some spermatozoa. In Baker's fluid, spermatozoa appeared normal under the light microscope but under the electron microscope, gross damage of the head membranes was seen (Pl. 2, Fig. 4). The whorls of the broken membrane may indicate that the outer membrane was under tension before disruption, but the nucleus and the subacrosomal substance remained intact. In half-strength Ringer, sperm motility was reduced and many tails were bent. Ultrastructural examination revealed detachment of the outer membrane over the tail and mid-piece regions as well as excessive disruption of the acrosome (PI. 2, Fig. 5).

Stefanini, Demartino \& Zamboni (1967) commented on the artefacts occurring during the preparation of human spermatozoa for electron microscopy and it is possible that chinchilla spermatozoa are similarly affected, but it is clear that the chinchilla outer membrane is less robust in Baker's fluid and halfstrength Ringer than in normal or double-strength Ringer.

Our thanks are due to Dr I. W. Rowlands for his encouragement, to Dr L. G. Goodwin for electron microscope facilities at the Nuffield Institute of Comparative Medicine and to Dr H. M. Dott for critically reading our original manuscript. Financial support was received from the Ford Foundation for the maintenance of the animals and for a personal Studentship to one of us (B.J.W.)

\section{EXPLANATION OF PLATE 1}

Figs. 1 to 3 are electron micrographs of chinchilla spermatozoa fixed directly in osmium tetroxide and stained with lead citrate. $\mathbf{A C}=$ acrosome; $\mathbf{A T}=$ acrosome termination; $\mathbf{C}=$ centriole; $\mathrm{CD}=$ cytoplasmic droplet; $\mathrm{EDF}=$ electron-dense fibres; $\mathbf{M}=$ mitochondria; $\mathbf{M F}=$ main fibres; $N=$ nucleus; $\mathrm{OM}=$ outer membrane; $\mathbf{S A S}=$ subacrosomal substance.

Fig. 1. Sagittal section of anterior end of head. Places where the membranes can be seen as double-layered are arrowed. $\times 60,000$.

FIG. 2. Sagittal section of neck region. $\times 40,000$.

Fig. 3. Longitudinal section of spermatozoon at junction between mid-piece and tail regions. Note that there is no distinct annulus. $\times 40,000$. 
PLATE 1

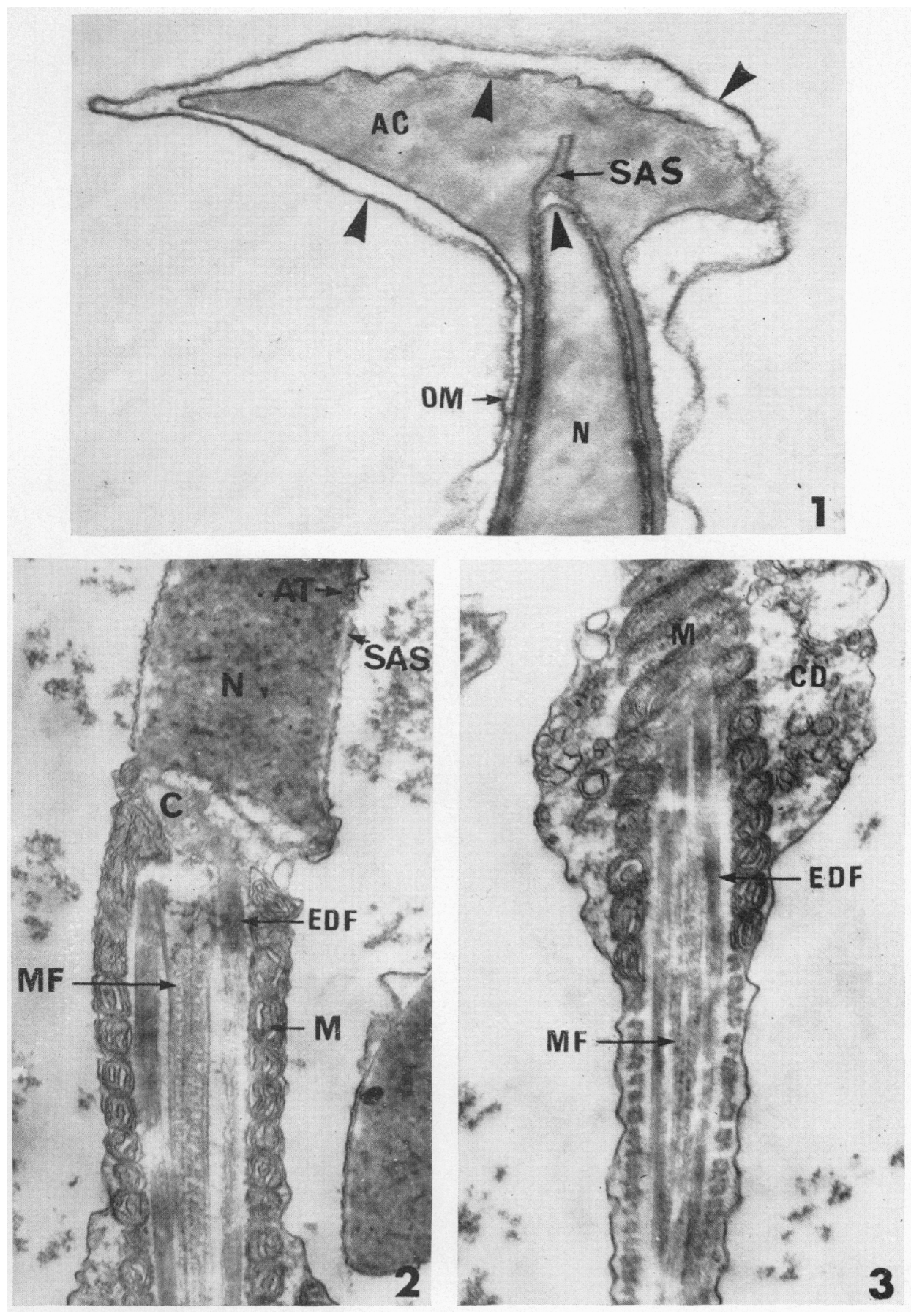

(Facing p. 192) 
PLATE 2
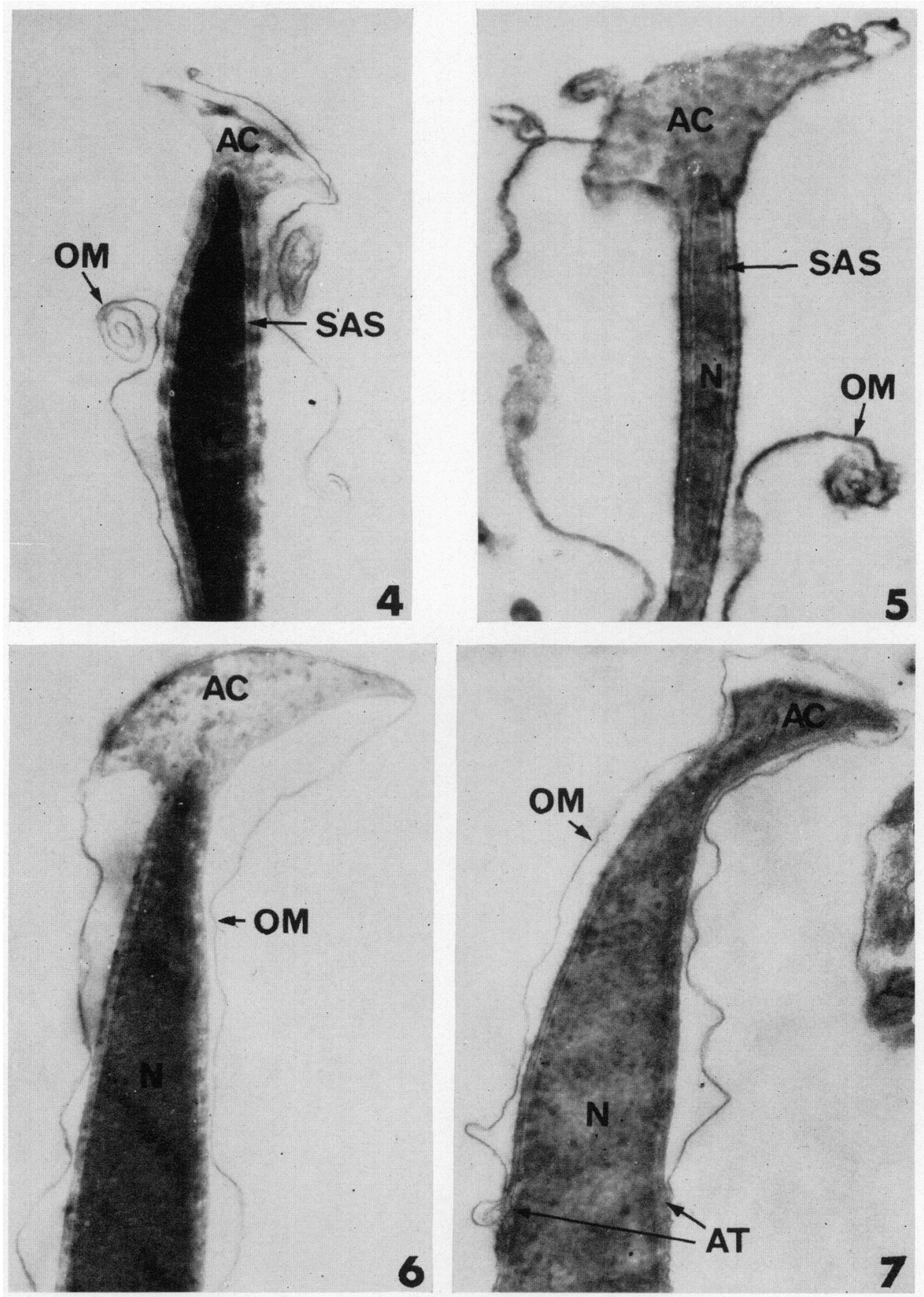

(Facing p. 193) 


\section{REFERENGES}

BakeR, J. R. (1931) An improved fluid for mammalian sperm suspensions. Q. Fl exp. Physiol. 21, 139.

FAwCETr, D. W. (1965) The anatomy of the mammalian spermatozoon with particular reference to the guinea-pig. Z. Zellforsch. mikrosk. Anat. 67, 279.

Fawcett, D. W. \& Phillips, D. M. (1969) Observations on the release of spermatozoa and on changes in the head during passage through the epididymis. F. Reprod. Fert. Suppl. 6, 405.

Glauert, A. M. \& Glauert, R. H. (1958) Araldite, an embedding medium for electron microscopy. 7. biophys. biochem. Cytol. 4, 191.

Healey, P. (1969) Effect of freezing on the ultrastructure of the spermatozoon of some domestic animals. 7. Reprod. Fert. 18, 21.

HeAley, P. \& WEIR, B. J. (1967) A technique for electro-ejaculation in chinchillas. F. Reprod. Fert. 13, 585.

NICANDER, L. \& BANE, A. (1966) Fine structure of the sperm head in some mammals with particular reference to the acrosome and subacrosomal substance. Z. Zellforsch. mikrosk. Anat. 72, 496.

Patade, G. E. (1952) Study of fixation for electron microscopy. F. exp. Med. 95, 285.

PIKo, L. \& TyLer, A. (1964) Fine structural studies of sperm penetration in the rat. Proc. Vth int. Cong. Anim. Reprod., Trento, $2,372$.

Reynolds, E. S. (1963) The use of lead citrate at high $\mathrm{pH}$ as an electron opaque stain in electron microscopy. F. Cell Biol. 17, 208.

Stepanini, M., Demartino, C. \& Zamboni, L. (1967) Fixation of ejaculated spermatozoa for electron microscopy. Nature, Lond. 216, 173.

\section{EXPLANATION OF PLATE 2}

Figs. 4 to 7 are electron micrographs of unstained chinchilla spermatozoa after treatment in various salt solutions and fixation in osmium tetroxide. $\mathrm{AC}=$ acrosome; $\mathrm{AT}=$ acrosome termination; $\mathbf{N}=$ nucleus; $\mathrm{OM}=$ outer membrane; $\mathrm{SAS}=$ subacrosomal substance.

FIG. 4. Sagittal section of head after $10 \mathrm{~min}$ in Baker's fluid. Note the whorls formed by the broken outer membrane and the start of acrosome deterioration. $\times 40,000$.

Fre. 5. Sagittal section of head after $10 \mathrm{~min}$ in half-strength Ringer's solution. The acrosome is disintegrating and the outer membranes have broken and formed whorls. $\times 40,000$.

FIG. 6. Sagittal section of head after $10 \mathrm{~min}$ in normal Ringer solution showing fairly normal appearance. $\times 40,000$.

Fig. 7. Sagittal section of head after $10 \mathrm{~min}$ in double-strength Ringer's solution. A normal appearance is presented although some spermatozoa showed slight membrane detachment in this diluent. $\times 40,000$. 